\title{
An Experimental Analysis of EMI Shielding Effectiveness using Multi layered Metal Meshed Reinforced Sustainable Foam
}

\author{
Asim Sneh ${ }^{1}$, Prem Thakur ${ }^{1}$, Kunal Yadav ${ }^{1}$, Ritesh Goyal ${ }^{1}$, Manshu Gupta ${ }^{1}$ \\ ${ }^{1}$ B. Tech Mechanical Engineer, \\ School of Mechanical Engineering, VIT CHENNAI \\ Vandalur - Kelambakkam road, Chennai, Tamil Nadu - 600127
}

\begin{abstract}
Organic foams are fabricated using a general mixing process incorporated with fine grid metal mesh inside it. The physical and chemical properties and the electromagnetic shielding effectiveness of these foams are investigated. The FTIR results indicate the presence of different organic functional groups. The sample with copper mesh was found to have the best EMI shielding effectiveness followed by brass, iron, and steel meshed samples. The average return loss in $\mathrm{dB}$ for a singlelayered sample with copper mesh was found to be around 28.715 $\mathrm{dB}$ and the average shielding effectiveness was found to be around $29.006 \mathrm{~dB}$ in the range of 8-12 $\mathrm{GHz}$. The multilayered mesh samples showed better results than single-layered samples.
\end{abstract}

Keywords-Organic Foam, Electromagnetic Interference (EMI) Shielding, Frequency, Fine Metal mesh

\section{INTRODUCTION}

The increasing complexity of electronic devices or systems in the form of higher packing density for quick response has resulted in electromagnetic interference ${ }^{[1]}$. Electromagnetic interference (EMI) or Radiofrequency interference is the noise that is resulted due to unwanted radiated signals caused by a wide range of electronic devices. The problem of EMI becomes prominent with the increase in the complexity of electronic devices or systems which has a high packing density for a quick response. Thus, it not only affects the performance of the device but also causes its degradation ${ }^{[2]}$ So, it becomes important to research on the performance features of the potential EMI shielding materials ${ }^{[3-5]}$.

The material chosen must not have any unfavorable impact on the performance of the equipment. It should not trade off the efficiency of the equipment with the EMI shielding or hinder any of its workings. So other properties of the material such as flexibility, mechanical and thermal stability must be decent enough to give it a real industrial application and not just theoretical concept ${ }^{[6],[11] \text {. }}$

Considering all the factors reinforced organic foams are believed to serve the purpose. They are lightweight, flexible and eco-friendly. Four samples are synthesized with organic foam as the base and different metal meshes (Steel, Iron, Copper, Brass) as the reinforcement. Various techniques are used to obtain the properties of the samples and a Shielding Effectiveness test setup is used for testing the EMI shielding capability of the material. A comparative study has been carried out to contrast with different samples.

\section{EXPERIMENTL PROCEDURE}

\section{A. Fabrication of Meshed Foam}

Samples are prepared with single, double and triple layers of Steel, Iron, Copper, and Brass mesh reinforced in flexible foam. First of all, some identical wooden molds are created with five sides closed and one side open. The open side is mounted with a fixture for holding the mesh of grid size $1 \mathrm{~mm}$ in the middle of the mold. The walls of the mold are waxed to facilitate the easy removal of the foam after preparation. After fixing the metal mesh on the fixture, a mixture of isocyanides and polyol of ratio 2:3 is put into the mold and the reaction is allowed to take place. The reaction is exothermic and carbon dioxide gas is released as a byproduct. In the multi-layered meshed foams, the distance between the adjacent meshes is $3 \mathrm{~mm}$.

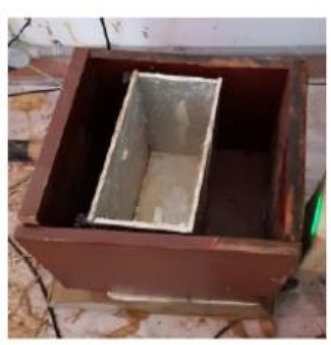

Fig. 1. Specimen Mould

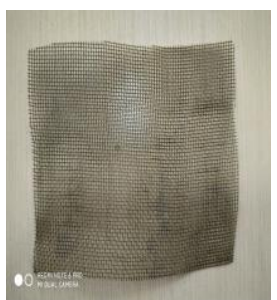

(a) Brass Mesh

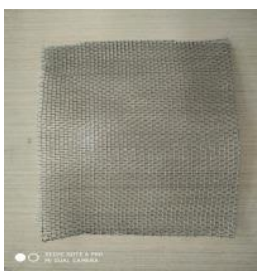

(c) Steel Mesh

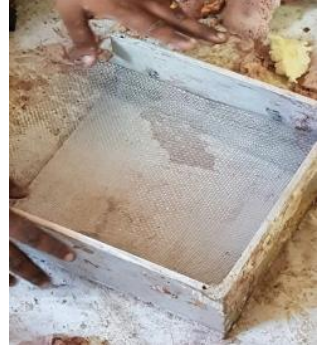

Fig. 2. Al tray with wax on surface

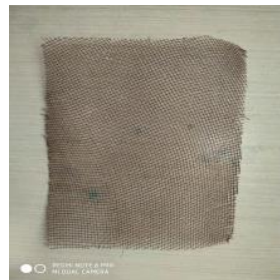

(b) Copper Mesh

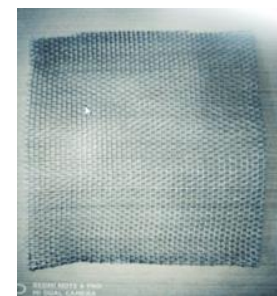

(d) Iron Mesh
Fig. 3. Different Metal Meshes 


\section{B. EMI shielding test Setup}

The electromagnetic interference (EMI) shielding effectiveness is measured by using an experimental setup consisting of a transmitter transmitting radiation of $8 \mathrm{GHz}$ $12 \mathrm{GHz}$ and a receiver. A spectrum analyzer is used to generate a plot of the Shielding Effectiveness (SE) of the sample being tested. In this setup, the transmitter and the receiver are placed $30 \mathrm{~cm}$ apart excluding sample thickness and the sample is placed in between as shown in the photograph. The plot is obtained on the analyzer for the frequency range of $8 \mathrm{GHz}-12 \mathrm{GHz}$.

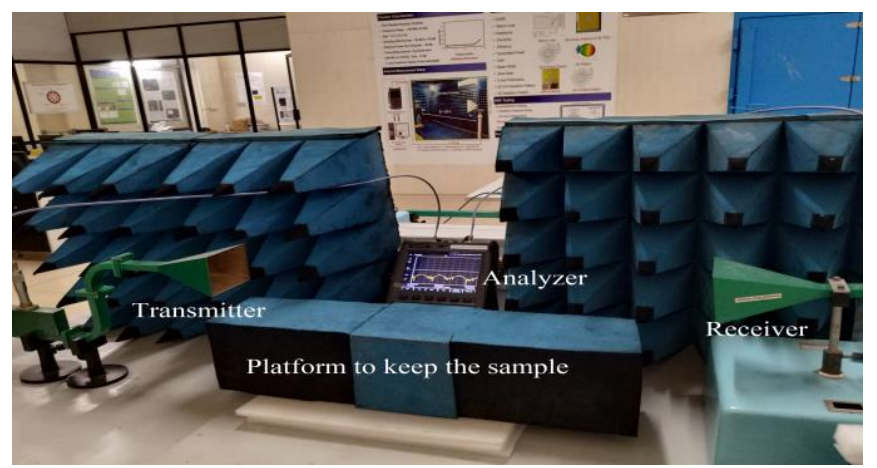

Fig. 4. Experimental Setup

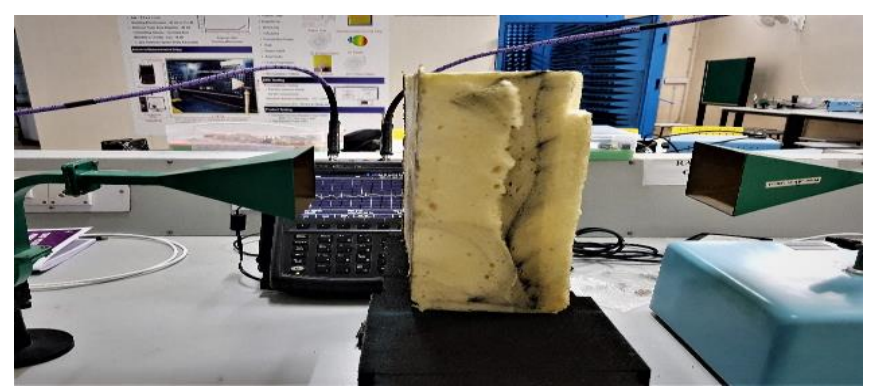

Fig. 5. Setup for meshed sample

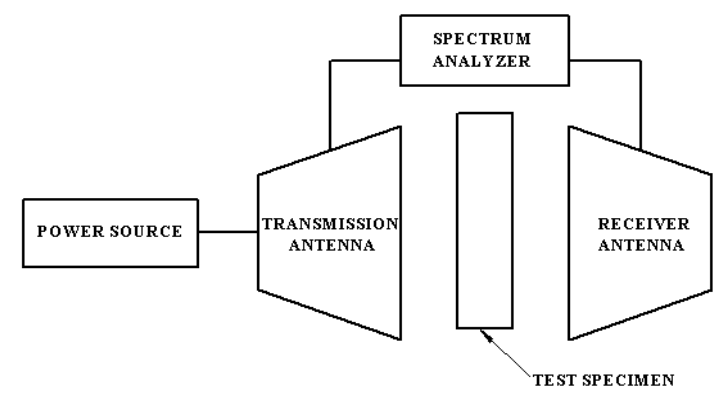

Fig. 6. Schematic Diagram of Setup

\section{FORMULA}

The theoretical quantification of EMI shielding effectiveness as express in the literature [7-10] are as follows:

Transmission coefficient, $(\mathbf{T})=\left|\mathbf{S}_{21}\right|^{2}$;

$\mathrm{S}_{21}=$ Spectrum Parameter of different PU Foams or also called the return loss

\section{A. FTIR Test}

IV. RESULTS AND DISCUSSION

According to the plot obtained from the Fourier Transformation Infrared (FTIR) Spectrum, we have verified the functional groups present in the different foams. The plots obtained is shown below.

- Flexible Foam: In the below graph, we can observe the broadening of the peaks in the range near $3500 \mathrm{~cm}^{-1}$ which confirms the presence of $-\mathrm{OH}$ functional group. The stretching of the peaks near the range of $3000 \mathrm{~cm}^{-1}$ confirms the presence of $-\mathrm{C}-\mathrm{H}$ groups. The absorption in the range of 2165-2110 $\mathrm{cm}^{-1}$ shows the presence of cyanide group.

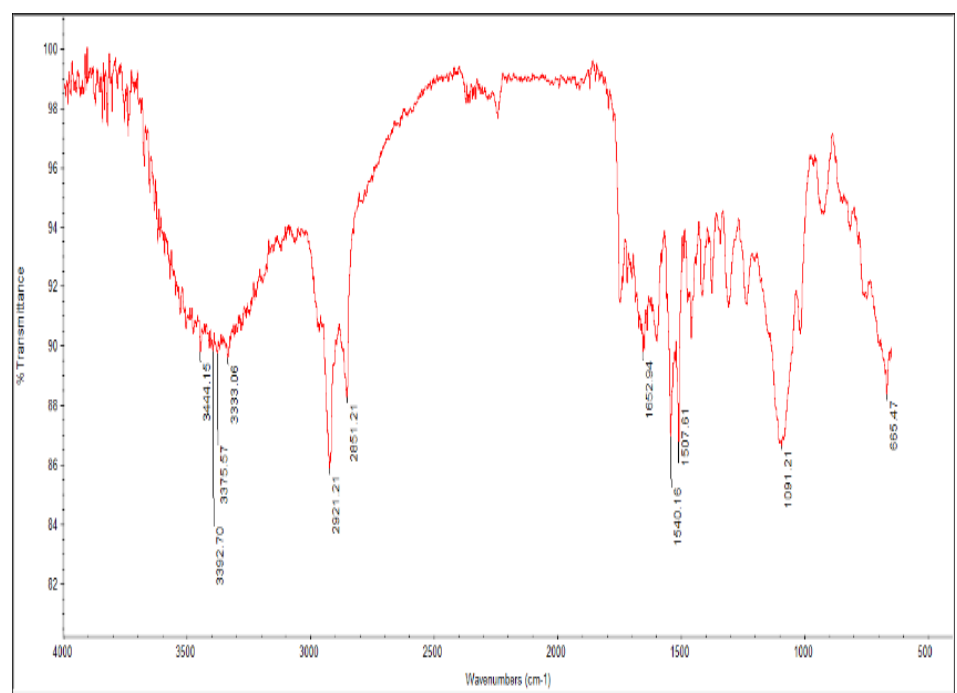

Fig. 7. Flexible Organic Foam (FTIR)

\section{B. EMI Shielding Performance Test}

The result of the EMI Shielding performance test was obtained in the form of a graph as shown in figures $8,9,10$, 11 and 12. The results have been summarized in Table 1.

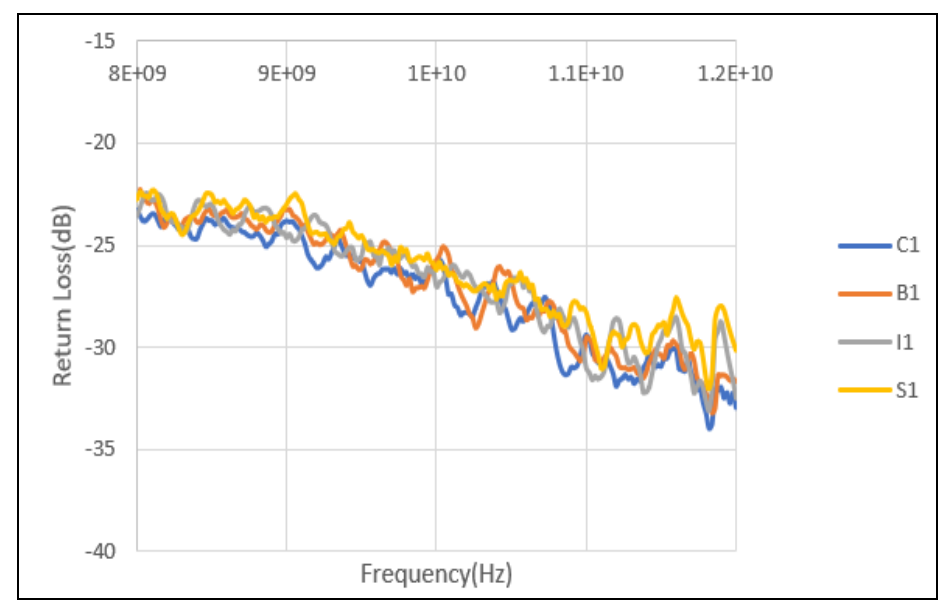

Fig 8. Comparison of Shielding Effectiveness(SE) of different metal meshes in the Organic Foam

Shielding Effectiveness $(S E)_{\text {total }}=10 * \log (1 / T)[d B]$ 


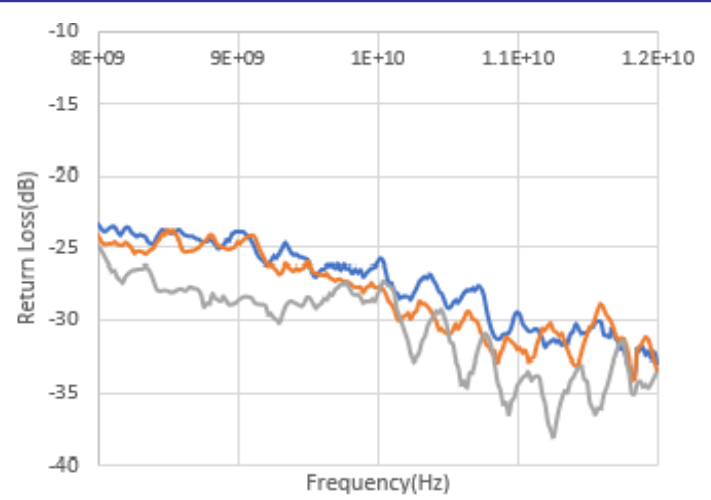

Fig 9. Comparison of Shielding Effectiveness(SE) of single, double and triple layer of copper mesh in the Organic Foam
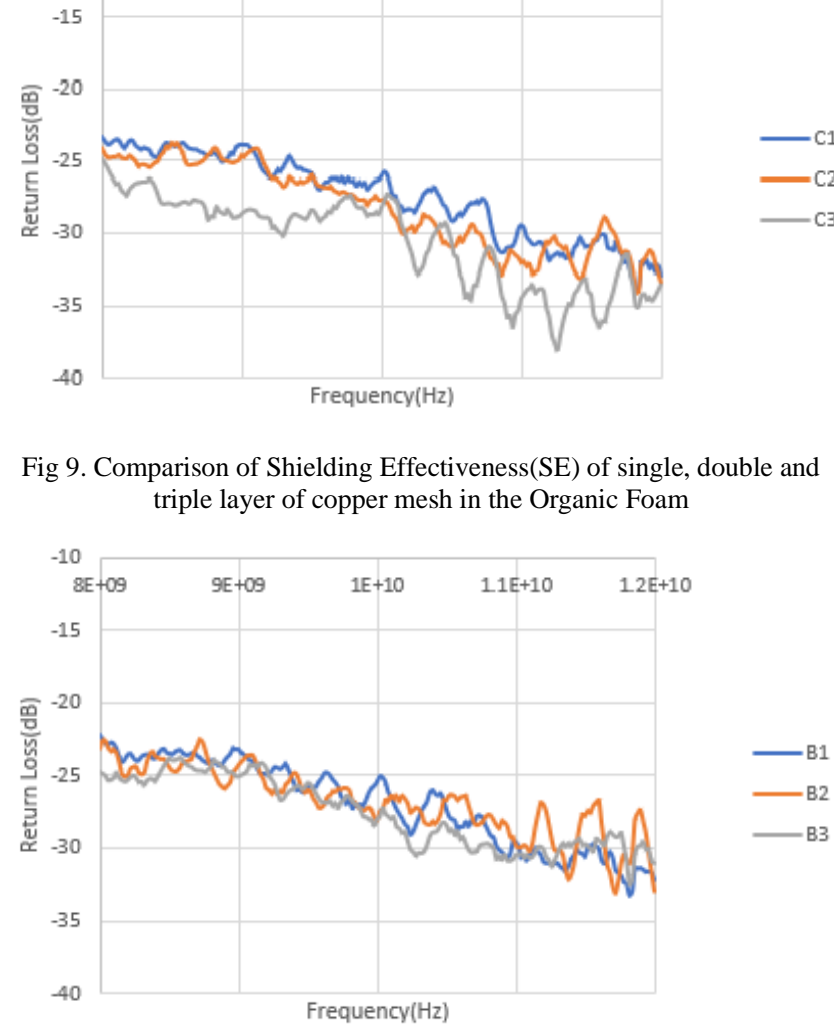

Fig 10. Comparison of Shielding Effectiveness(SE) of single, double and triple layer of brass mesh in the Organic Foam

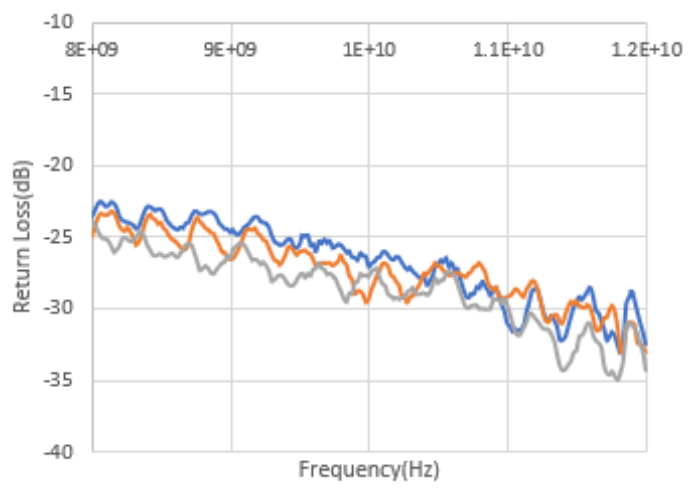

Fig 11. Comparison of Shielding Effectiveness(SE) of single, double and triple layer of Iron mesh in the Organic Foam

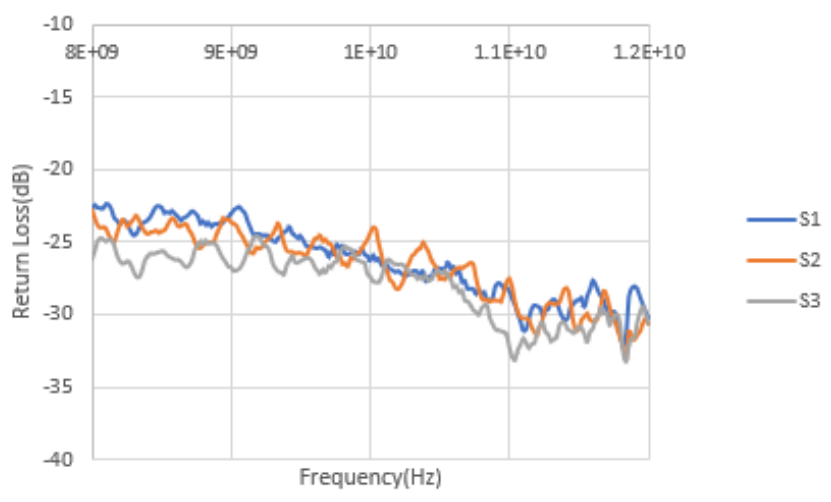

Fig 12. Comparison of Shielding Effectiveness(SE) of single, double and triple layer of Steel mesh in the Organic Foam
Table 1: Shielding Performance Test Quantification

\begin{tabular}{|c|c|c|c|}
\hline Sample & $\begin{array}{c}\text { Frequency } \\
\text { Range } \\
\text { GHz }\end{array}$ & $\begin{array}{l}\text { Return Loss } \\
\text { (dB) }\end{array}$ & $\begin{array}{c}(S E)_{\text {total }} \\
(\mathbf{d B})\end{array}$ \\
\hline $\mathrm{C} 1$ & $8-12$ & $\begin{array}{c}(-34.106) \\
- \\
(-23.325)\end{array}$ & $(-30.657)-(-27.356)$ \\
\hline B1 & $8-12$ & $\begin{array}{c}(-33.258) \\
- \\
(-22.242)\end{array}$ & $(-30.438)-(-26.943)$ \\
\hline I1 & $8-12$ & $\begin{array}{c}(-33.102) \\
- \\
(-22.491)\end{array}$ & $(-30.397)-(-27.040)$ \\
\hline S1 & $8-12$ & $\begin{array}{c}(-32.064) \\
- \\
(-22.337)\end{array}$ & $(-30.120)-(-26.980)$ \\
\hline $\mathrm{C} 2$ & $8-12$ & $\begin{array}{c}(-34.563) \\
- \\
(23.775) \\
\end{array}$ & $(-30.772)-(-27.522)$ \\
\hline B2 & $8-12$ & $\begin{array}{c}(-33.232) \\
- \\
(-22.501)\end{array}$ & $(-30.411)-(-27.044)$ \\
\hline I2 & $8-12$ & $\begin{array}{c}(-33.069)- \\
(-23.215)\end{array}$ & $(-30.388)-(-27.315)$ \\
\hline S2 & $8-12$ & $\begin{array}{c}(-32.996)- \\
(-22.814)\end{array}$ & $(-30.369)-(-27.164)$ \\
\hline $\mathrm{C} 3$ & $8-12$ & $\begin{array}{c}(-38.098)- \\
(-24.810)\end{array}$ & $(-31.618)-(-27.893)$ \\
\hline B3 & $8-12$ & $\begin{array}{c}(-33.532)- \\
(-23.830)\end{array}$ & $(-30.509)-(-27.542)$ \\
\hline I3 & $8-12$ & $\begin{array}{c}(-34.432)- \\
(-23.828)\end{array}$ & $(-30.483)-(-27.542)$ \\
\hline S3 & $8-12$ & $\begin{array}{c}(-33.292)- \\
(-24.567)\end{array}$ & $(-30.446)-(-27.807)$ \\
\hline
\end{tabular}

The negative value of shielding effectiveness merely represents the loss of EM wave power concerning the incident EM wave. The comparison should be made based on the absolute value of the shielding effectiveness. According to the graphs obtained from the EMI shielding effectiveness experiment, the foam with the copper mesh was found to have the maximum shielding effectiveness followed by brass, iron and steel sample.

The single layered samples have little less Shielding Effectiveness in comparison to multilayered samples. And among all, the samples with copper mesh have better SE followed by brass, Iron and steel which is around $32 \mathrm{dBs}$.

\section{CONCLUSIONS}

The physical and chemical properties of the samples are found, and the shielding effectiveness is characterized using the EMI shielding test.

- The sample with copper mesh was found to have the maximum shielding effectiveness followed by the sample with brass, iron and steel meshes.

- Multilayered samples have little more shielding effectiveness then single layered samples.

- The machinability of the shielding material is improved because of the meshes. Now it is easy to shape the shielding material into different shapes and retain the same.

- Thus, we can derive from our investigation that in the frequency range of $8 \mathrm{GHz}-12 \mathrm{GHz}$ the flexible foam with different meshes can be actively used to 
provide effective shielding for satellite communication body parts covering radio navigation and data transfer and operations.

- As brass alloy has better $(\mathrm{SE})_{\mathrm{t}}$ in comparison to pure metals such as iron and steel so this research work opens the gate for further investigation

\section{ACKNOWLEDGEMENT}

We are thankful to VIT-CHENNAI for providing us with resources and fully equipped laboratory for carrying out the experiments. We are also thankful to the mentor, guide, coauthor Dr. Jeyanthi Subramaniam and her research scholar Mr. Yuvraj for helping and providing us with basics and knowledge for the study of the results and its development.

\section{NOMENCLATURE}

\section{C1: PU foam sample with single layer of copper mesh}

\section{C2: PU foam sample with double layer of copper mesh}

\section{C3: PU foam sample with triple layer of copper mesh}

B1: PU foam sample with single layer of Brass mesh

\section{B2: PU foam sample with double layer of Brass mesh}

B3: PU foam sample with triple layer of Brass mesh

I1: PU foam sample with single layer of Iron mesh

I2: PU foam sample with double layer of Iron mesh

I3: PU foam sample with triple layer of Iron mesh

S1: PU foam sample with single layer of Steel mesh

S2: PU foam sample with double layer of Steel mesh

S3: PU foam sample with triple layer of Steel mesh SE: Shielding Effectiveness

\section{REFERENCES}

[1] Mordiguine, M. Interference Control in Computer and Microprocessors Based Equipment's; Don White Consultant Inc.: Virginia, 1984.

[2] Violette, J. L. N.; White, D. R. J.; Violette, M. F. Electromagnetic Compatibility Handbook; Van Nostrand Reinhold Company: New York, 1987.

[3] F. Moglie, D. Micheli, S. Laurenzi, M. Marchetti, V.M. Primiani, Carbon 50 (2012) 1972-1980.

[4] M. Jalali, S. Dauterstedt, A. Michaud, R. Wuthrich, Compos. Part BEng. 42 (2011) 1420-1426.

[5] W. Jou, H. Cheng, C. Hsu, J. Alloys Comp. 434-435 (2007) 641645 .

[6] S. Mathew, P.R. Rejikumar, J. Yohannan, K.T. Mathew, N.V. Unnikrishnan, J. Alloys Comp. 462 (2008) 456-459.

[7] A self-assembled graphene/polyurethane sponge for excellent electromagnetic interference shielding performance†; Zhikang $\mathrm{Hu}$, XinXin Ji, Buyin Li, Yuanzheng Lou, RSC Adv.2009.

[8] Calculation of Shielding Effectiveness of Materials for Security Devices; Stanislav Kovar, Jan Valouch and Hana Urbancokova;

051/, 02036 (2017) 712501MATEC Web of Conferences 25 matecconf/201 CSCC 2017203

[9] Electrical Conductivity and Electromagnetic Shielding Effectiveness Of Silicone Rubber Filled With Ferrite And Graphite Powders; C. Morari*, I. Balan, J. Pintea, E. Chitanu, and I. Iordach; Progress In Electromagnetics Research M, Vol. 21, 93-104, 2011.

[10] EMI Shielding: Methods and Materials-A Review; S. Geetha, Chepuri R. K. Rao; M. Vijayan; konda kannan satheesh kumar; Journal of Applied Polymer Science 112(4):2073 - 2086 . May 2009.

[11] Three Dimensional and Highly Ordered Porous Carbon-MnO2 Composite Foam for Excellent Electromagnetic Interference Shielding Efficiency; Pinki Rani Agarwala,b, Rajeev Kumarc, Saroj Kumaria, Sanjay R. Dhakatea,b*; DOI: 10.1039/ C6RA23127F

\section{AUTHOR'S PROFILE}
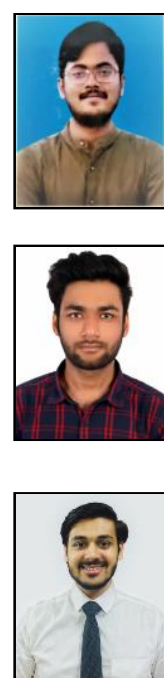

Kunal Yadav: B.Tech Mechanical Engineer, School of Mechanical Engineering Chennai (SMEC), Vellore Institute of Technology Chennai. Research areas are Carbon Fibre Composites, EMI sheilding and Acoustic properties of materials.

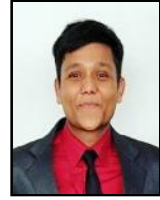

Ritesh Goyal: B.Tech Mechanical Engineer, School of Mechanical Engineering Chennai (SMEC), Vellore Institute of Technology Chennai. Research areas are Interna combustion engines (Gasoline performance and emissions, Real Driving Emissions, Legislation); Mathematical modelling \& ML for mobility sector; Electrified Drivetrains; Shock physics.

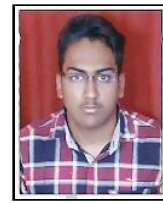

Manshu Gupta: B.Tech Mechanical Engineer, School of Mechanical Engineering Chennai (SMEC), Vellore Institute of Technology Chennai. Research areas are internal combustion engines, nanopaticles, EMI and acoustics materials development. Published 2 articles in reputed international journals. 